\title{
Pulmonary and systemic fungal infections in an Atlantic spotted dolphin and a Bryde's whale, Brazil
}

\author{
Kátia R Groch ${ }^{1, *}$, Josué Díaz-Delgado ${ }^{1,2}$, Carlos Sacristán $^{1}$, Denyiélim E. Oliveira ${ }^{3}$, \\ Gabriela Souza ${ }^{3}$, Angélica M. Sánchez-Sarmiento ${ }^{1}$, Samira Costa-Silva ${ }^{1}$, \\ Juliana Marigo ${ }^{1}$, Pedro V. Castilho ${ }^{3}$, Marta J. Cremer ${ }^{4}$, Aline Rodrigues Hoffmann ${ }^{2}$, \\ Fernando Esperón ${ }^{5}$, José L. Catão-Dias ${ }^{1}$ \\ ${ }^{1}$ Laboratory of Wildlife Comparative Pathology, Department of Pathology, \\ School of Veterinary Medicine and Animal Science, University of São Paulo, São Paulo, SP 05508-270, Brazil \\ ${ }^{2}$ Department of Veterinary Pathobiology, College of Veterinary Medicine and Biomedical Sciences, Texas A\&M University, \\ College Station, TX 77845, USA \\ ${ }^{3}$ Departamento de Engenharia de Pesca, Universidade do Estado de Santa Catarina, Bairro Progresso, Laguna, \\ SC 88.790-000, Brazil \\ ${ }^{4}$ Laboratório de Nectologia, Universidade da Região de Joinville, UNIVILLE, São Francisco do Sul, SC 89240-000, Brazil \\ ${ }^{5}$ Grupo de Epidemiología y Sanidad Ambiental, Centro de Investigación en Sanidad Animal (INIA-CISA), Valdeolmos, \\ Madrid 28130, Spain
}

\begin{abstract}
We report the gross and microscopic findings and molecular identification of 2 cases of hyphate fungal infection in cetaceans from Brazil. The first case involved an adult male Atlantic spotted dolphin Stenella frontalis with localized pulmonary disease characterized by pyogranulomatous and necrotizing bronchopneumonia with intralesional hyphae. The second case involved an adult male Bryde's whale Balaenoptera edeni with orchitis, periorchitis, mesenteric lymphadenitis and pyogranulomatous bronchopneumonia with intralesional hyphae. PCR analysis from the dolphin's lung yielded Aspergillus fumigatus, and the fungus from the whale's mesenteric lymph node showed the greatest identity to Nanniziopsis obscura and Stagonosporopsis cucurbitacearum These cases represent the first reports of pulmonary aspergillosis by A. fumigatus in an Atlantic spotted dolphin and systemic mycosis by a possibly novel Onygenales in marine mammals.
\end{abstract}

KEY WORDS: Marine mammal - Balaenoptera edeni - Stenella frontalis · Cetacean pathology · Fungal infection $\cdot$ Mycosis $\cdot$ Onygenales $\cdot$ Nannizziopsiaceae $\cdot$ Aspergillus

Resale or republication not permitted without written consent of the publisher

\section{INTRODUCTION}

Fungal infections are a relatively minor cause of morbidity and mortality in free-ranging cetaceans when compared to viral and bacterial ailments; however, in captivity, mycosis incidence is higher and pharmacological treatment is often required due to potential systemic involvement. Several fungi have been associated with superficial colonization and with cutaneous, subcutaneous and deep infection (localized or disseminated) in cetaceans (Reidarson et al. 2001). Occasionally, despite isolation of potentially pathogenic fungi from bodily surfaces, mucocutaneous junctions, excreted 
products and internal mucosae, there is no evidence of clinical disease (Reidarson et al. 2001). Given their low transmissibility, mycoses are frequently endemic.

Most reported mycosis cases in cetaceans involve the skin, the lungs and the central nervous system (CNS). Regardless of the primary infection site, fungemia and dissemination are relatively common sequelae (Reidarson et al. 2001, Abdo et al. 2012). Although some fungi are known to act as primary pathogens in cetaceans, e.g. Blastomyces dermatitidis, Coccidioides immitis and Histoplasma capsulatum (Reidarson et al. 2001, Miller et al. 2002), most fungal infections are regarded as opportunistic (Reidarson et al. 2001, Mouton et al. 2015). The latter are often associated with inconspicuous or demonstrable immunosuppressive pathogens, such as cetacean morbillivirus (CeMV) (Domingo et al. 1992) and herpesvirus (Abdo et al. 2012), xenobiotics (e.g. persistent organic pollutants, inorganic compounds such as heavy metals) (Mouton et al. 2015) and malnutrition (Dagleish et al. 2008).

Fungi of varying medical importance in cetaceans may include class Zygomycetes, e.g. Mucor sp. (Naota et al. 2009), Rhizomucor pusillus (Reidarson et al. 2001), Cunninghamella bertholletiae, Saksenaea vasiformis and Apophysomyces elegans (Reidarson et al. 2001, Robeck \& Dalton 2002); class Saccharomycetes, e.g. Candida spp., mainly C. albicans (Reidarson et al. 2001); class Eurotiomycetes, e.g. Aspergillus spp., mainly A. fumigatus, Cladophialophora bantiana, H. capsulatum (Reidarson et al. 2001), Paraccocidioides brasiliensis (Lacazia loboi) (Vilela et al. 2016), Coccidioides immitis, B. dermatitides and Trichophyton sp. (Reidarson et al. 2001); class Sordariomycetes, e.g. Fusarium spp. and Sporothrix schenckii (Reidarson et al. 2001); and class Tremellomycetes, e.g. Cryptococcus neoformans var. neoformans and gattii (Reidarson et al. 2001, Miller et al. 2002) and Trichosporon pullulans (Reidarson et al. 2001).

Most descriptions of fungal infection in cetaceans have involved odontocetes; they are rarely reported in mysticetes (Best \& McCully 1979, McAloose et al. 2016). This study describes the gross and microscopic findings and molecular identification of 2 cases of hyphate fungal infection involving an Atlantic spotted dolphin Stenella frontalis and a Bryde's whale Balaenoptera edeni from Brazil. These cases represent the first reports of pulmonary aspergillosis by A. fumigatus in an Atlantic spotted dolphin and systemic mycosis by a possibly novel Onygenales in marine mammals.

\section{MATERIALS AND METHODS}

A $1.79 \mathrm{~m}$ long, adult male Atlantic spotted dolphin (Case 1) in poor nutritional status and moderate autolysis was found stranded dead in Laguna, Santa Catarina state (SC) (Brazil; 28 $28^{\circ} \mathrm{S}$, $48^{\circ} 45^{\prime} \mathrm{W}$ ), on 19 October 2016. A $13.12 \mathrm{~m}$ long, adult male Bryde's whale (Case 2) in apparent good nutritional status and moderate autolysis was found stranded dead in São Francisco do Sul, SC (Brazil; $26^{\circ} 13^{\prime} \mathrm{S}, 48^{\circ} 29^{\prime} \mathrm{W}$ ), on 23 June 2014. A standard necropsy was performed in both cases. Representative tissue samples from Case 1 (heart, lung, trachea, mediastinal and tracheobronchial lymph nodes, diaphragm, tongue, stomach, intestine, liver, kidney, urinary bladder, spleen, pancreas, testicle, epididymis, skin, rectus abdominis and longissimus dorsi) and Case 2 (aorta, heart, lung, baleen, tongue, gastric compartments, small and large intestine, mesenteric lymph nodes, testicle, optic nerve, skin, rectus abdominis and longissimus dorsi) were collected and fixed in 10\% neutral buffered formalin. All these tissues were processed routinely and embedded in paraffin, and $5 \mu \mathrm{m}$ sections were stained with hematoxylin and eosin (H\&E) for microscopic analysis. Selected tissue sections were also stained with Grocott and Gomori methenamine silver (GMS), periodic acid-Schiff (PAS), Gram/Twort and Masson's trichrome stains to better characterize the microscopic findings.

For molecular analysis of fungi, frozen tissues including lung (Cases 1 and 2) and mesenteric lymph node (Case 2), were selected. Briefly, the DNA was extracted from frozen tissues with a DNeasy Blood \& Tissue kit (Qiagen). A pan-polymerase chain reaction (pan-PCR) to amplify the internal transcribed spacer regions 1 and 2 (ITS-1 and ITS-2), including part of the 18S rRNA, the 5.8S rRNA and the 26S rRNA genes, was performed (White et al. 1990, Gardes \& Bruns 1993). After electrophoresis in $1.5 \%$ agarose gels, positive samples were identified through direct sequencing. Sequences were aligned on MEGA6, primer sequences were removed, and BLAST searches (www.ncbi.nlm.nih.gov/blast/Blast. cgi) of the edited sequences were performed. MEGA6 was selected to establish the identity of the sequenced material based on the p-distance between the obtained sequences and the closest sequences available in GenBank. Additionally, formalin-fixed paraffin-embedded (FFPE) tissue sections from the lung, peritesticular mass and mesenteric lymph node from case 2 were used for a panfungal PCR targeting the ITS1 region, followed by sequen- 
cing (Meason-Smith et al. 2017). Given potential immunosuppressive effects on host and occasional reports linking CeMV with fungal coinfections, conventional PCR analysis for CeMV was performed. RNA was extracted from frozen tissue samples (Case 1: lung, kidney; Case 2: lung and mesenteric lymph node) by using TRIzol Reagent (Life Technologies) according to the manufacturer's instructions. Reverse transcription PCR was performed targeting a conserved fragment of the phosphoprotein gene following a previously described method (Barrett et al. 1993).

\section{RESULTS}

Major gross findings in Case 1 included multifocal to coalescing $2.5 \times 2 \times 2 \mathrm{~cm}$ to $9 \times 6 \times 5 \mathrm{~cm}$, moderately well-demarcated, firm and cavitated pulmonary masses that had abundant yellow to dark grey, viscous to granular material (pyogranulomas) that occasionally centered and occluded small bronchi (Fig. 1A). The tracheobronchial and mediastinal lymph nodes were enlarged (up to $5 \times 4 \times 2.5 \mathrm{~cm}$ ) and the parenchyma was pale pink and bulging on its cut surface. Histopathological examination of lung tissue revealed severe, multifocally coalescing, chronic fibrinosuppurative to pyogranulomatous and necrotizing bronchopneumonia with bronchiectasis, bronchial/bronchiolar obliteration, chondritis, chrondronecrosis and chondrolysis with intralesional nonpigmented hyphae (Fig. 1B). Hyphae were 3-10 $\mu \mathrm{m}$ (in width) $\times 7-15 \mu \mathrm{m}$ (in length), displayed an arborizing growth pattern with progressive dichotomous acute-angle branching, regular septation and parallel, faded-to-hyalinized walls (Fig. 1Bi). Rarely, in areas of mycelial growth, hyphae were tangled, bulbous and distorted. Arteritis and phlebitis with fungal angioinvasion, vascular thrombosis and ischemic infarction were also noted. Varying degrees of fibrosis surrounded these inflammatory foci. In the tracheobronchial and mediastinal lymph nodes there was marked, diffuse lymphoid reactive hyperplasia and scattered foci of eosinophilic to pyogranulomatous inflammation associated with L3-L4 nematode larvae. PCR analysis and sequencing produced a 614 base pair (bp) sequence (excluding primers) further submitted to GenBank under accession number MF580951, with $100 \%$ nucleotide (nt) identity to several Aspergillus fumigatus previously described (e.g. GenBank accession numbers KX893912, HG936917, KR023997).

Main gross findings in Case 2 were focal subcutaneous hematomas in the right ventral cervical area, and left retromandibular and ventral-lateral abdomen; mild intestinal Bolbosoma spp. parasitism; and reddened lungs with pale tan nodules $1-2 \mathrm{~cm}$ in diameter. Histopathologically, there was marked,
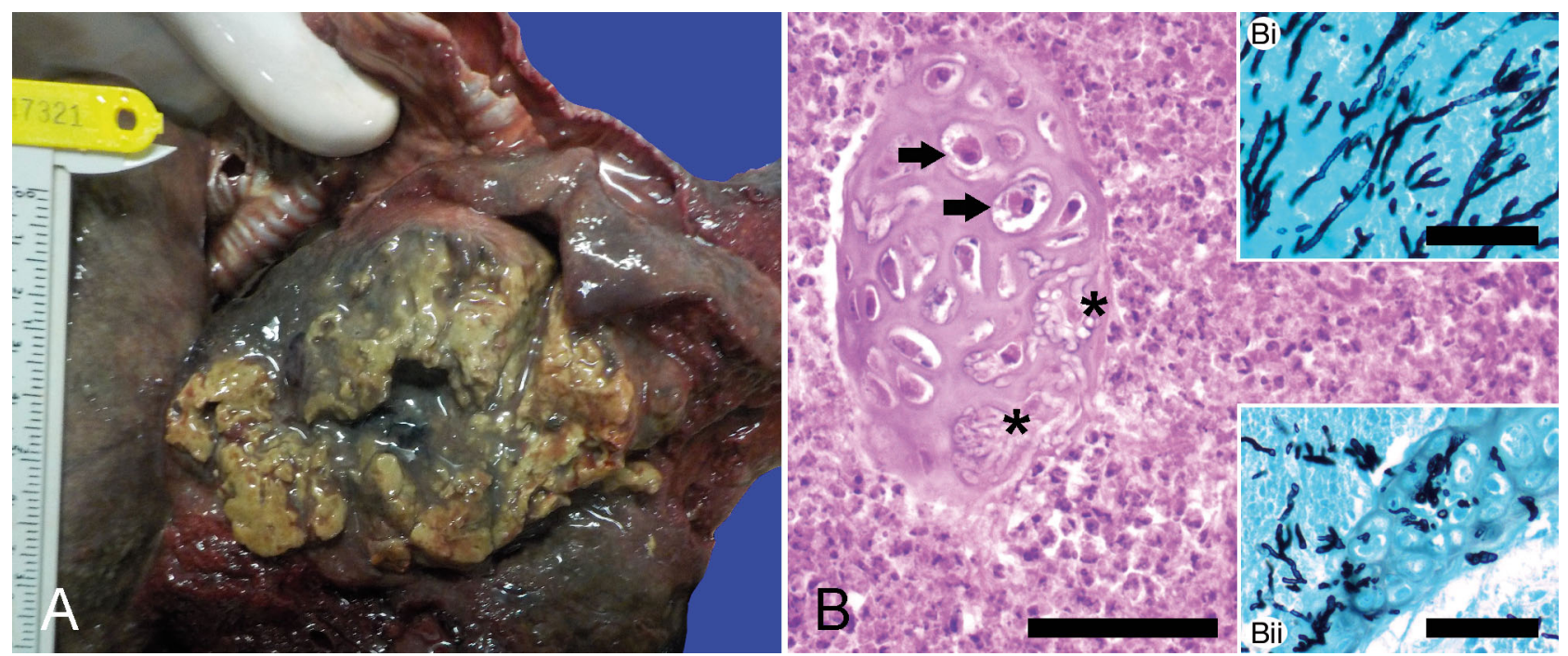

Fig. 1. Macroscopic and microscopic lesions found in an Atlantic spotted dolphin Stenella frontalis. (A) The ventral parenchyma of the left lung lobe is expanded and replaced by a locally extensive, cavitated mass with abundant necrosuppurative exudate. (B) Pyogranulomatous bronchitis with chondritis, chondrocyte necrosis (arrows), chondrolysis and intracartilage hyphae (asterisks). H\&E. Scale bar $=50 \mu \mathrm{m}$. (Bi) Hyphal arborizing growth pattern with progressive dichotomous branching at acute angles. Gomori methenamine silver (GMS). Scale bar $=50 \mu \mathrm{m}$. (Bii) Severe cartilage infiltration by hyphae. GMS. 
focally extensive, chronic pyogranulomatous and necrotizing orchitis and periorchitis. A leukocytoclastic necrotizing vasculitis was present in vessels with angioinvasive non-pigmented hyphae, hemorrhage and thrombosis (Fig. 2A). There was marked, diffuse, chronic pyogranulomatous and necrotizing mesenteric lymphadenitis with vasculitis, thrombosis, ischemic infarction and numerous hyphae within the subcapsular, cortical and medullary sinuses (Fig. 2B). In the lung, multifocal pyogranulomatous bronchopneumonia contained intralesional hyphae. Fungal populations differed in the lung and lymph node compared to the testis. In the inflamed testicle, tunica albuginea and tunica vaginalis, hyphae were 3-10 $\mu \mathrm{m} \times 8-15 \mu \mathrm{m}$, elongate to oval, with nondichotomous acute to straight-angle branching and parallel thin walls (Fig. 2Ai). In the inflamed mesenteric lymph node and lung, hyphae were 3-12 $\mu \mathrm{m} \times$ 13-17 $\mu \mathrm{m}$, typically oval to elongate, having regular, parallel and faded to hyalinized walls, with typically straight angle, non-dichotomous branching. The fungi also showed few ascomatal initials (inflated, up to $8 \mu \mathrm{m} \times 15 \mu \mathrm{m}$ irregular cells with secondary proliferations), vesicular swellings, occasional undulate hyphal branches and chains of arthroconidia (3-7 $\mu \mathrm{m} \times 4-6 \mu \mathrm{m}$ slightly barrel-shaped cells) and aleurioconidia (slightly pyriform cells measuring 3-6 $\mu \mathrm{m} \times 2-5 \mu \mathrm{m}$ and often subtended by slightly swollen cells from conidial chains) (Fig. 2Bi-iii).
Additional histological findings included: marked, multifocal, acute myocyte segmental hyaline necrosis with discoid pattern, edema and hemorrhage in the rectus abdominis and longissimus dorsi; alveolar microlithiasis and rare fibrin thrombi; and moderate pyogranulomatous enteritis with intralesional adult Bolbosoma sp. Pan-fungal-PCR of the mesenteric lymph node and lung yielded 2 sequences of 922 and $562 \mathrm{bp}$, respectively. The sequence from the mesenteric lymph node presented the greatest nucleotide identity $(85.4 \%$ and $85.3 \%$, respectively) to a sequence initially identified as Nannizziopsis vriesii (HF547869), but also related to $N$. obscura (Steininger et al. 2005, Sigler et al. 2013), and to $N$. obscura (NR111878), both sequences originally identified in infected humans. A higher identity to a Stagonosporopsis cucurbitacearum (syns. Didymella bryoniae, Phoma cucurbitacearum, Sphaeria bryoniae) $(99.1 \%$ to a $S$. cucurbitacearum strain, JQ93 6151) was observed to the sequence obtained from the lung of the Bryde's whale. The possibly novel sequence of Onygenales, suggestive of Nannizziopsiaceae, and $S$. cucurbitacearum were submitted to GenBank under accession numbers MF688808 and MF580997, respectively. PCR analysis from FFPE tissues yielded a single band with approximately $350 \mathrm{bp}$. Sequences were of poor quality and did not match any fungal sequences on BLAST-NCBI. CeMV RT-PCR was negative.
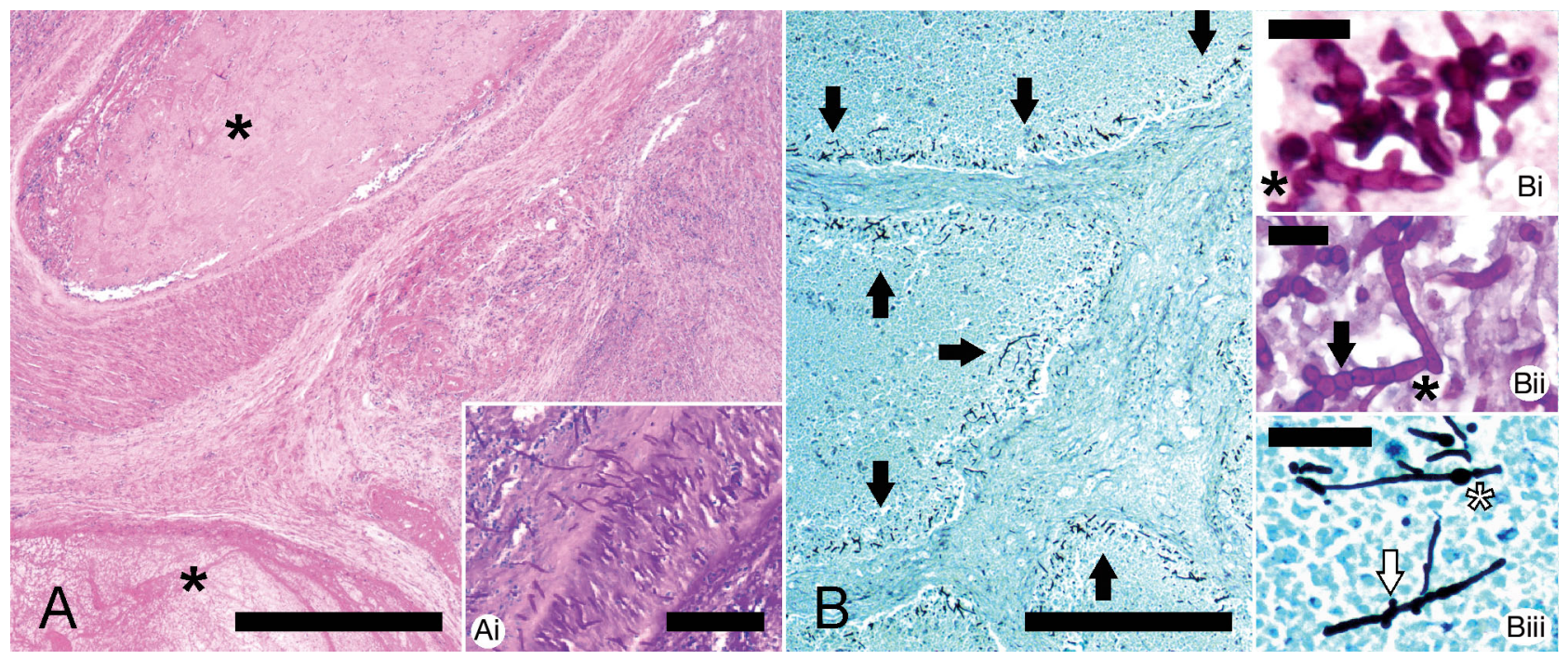

Fig. 2. Microscopic lesions found in a Bryde's whale Balaenoptera edeni. (A) Periorchitis with obliterative fibrinocellular thrombosis (asterisks). H\&E. Scale bar $=200 \mu \mathrm{m}$. (Ai) Fungal angioinvasion. Periodic acid-Schiff (PAS). Scale bar $=50 \mu \mathrm{m}$. (B) Numerous fungal hyphae infiltrate the medullary sinuses of the mesenteric lymph (arrows). GMS. Scale bar $=100 \mu \mathrm{m} .(\mathrm{Bi})$ Fungal ascomatal initial with focal undulating hyphal branch (asterisk). PAS. Scale bar $=20 \mu \mathrm{m}$. (Bii) Chain of arthroconidia (arrow) attached to branching hyphae (asterisk). PAS. Scale bar $=20 \mu \mathrm{m}$. (Biii) Focal hyphal vesicular swelling (asterisk) and occasional aleurioconidia (arrow). GMS. Scale bar $=50 \mu \mathrm{m}$ 
The combination of moderate to severe pathologic findings and molecular results supports the pathogenic potential of $A$. fumigatus in Case 1, and suggests that a novel Onygenales, with greatest nucleotide identity to Nannizziopsiaceae, affect marine mammal species.

\section{DISCUSSION}

Mycotic diseases are increasingly reported worldwide and sporadically lead to emerging infections (Reidarson et al. 2001, Guarner \& Brandt 2011). Diagnosis often hinges on histological examination of a dead animal. Although fungal classification by histopathology can be difficult, for some fungi such as Aspergillus the distinct morphology of fruiting bodies may allow accurate histopathologic speciation. Additional histochemical stains (GMS, PAS, mucicarmine), coupled with immunohistochemistry and in situ hybridization, may aid in histological fungal classification (Guarner \& Brandt 2011); PCR provides more definitive speciation. Culture is a preferable ancillary test, but not all species are cultivable, such as Paracoccidioides brasiliensis of dolphin origin (Vilela et al. 2016).

Aspergillus is a ubiquitous saprophytic fungus that typically acts as an opportunist pathogen in debilitated and immunocompromised animals. Pulmonary aspergillosis has been linked to immune disorders; allergic bronchopulmonary disease; bronchocentric granulomatosis; hypersensitivity pneumonitis; bronchitis and chronic necrotizing pneumonia; fungus balls; and angioinvasive disease (Guarner \& Brandt 2011). Multiple Aspergillus species have been linked to primary diseases in cetaceans and may have different routes of entry. A. fumigatus infection has been reported in the CNS in several odontocetes (Reidarson et al. 2001, Dagleish et al. 2008) and respiratory tree in striped dolphins Stenella coeruleoalba (Reidarson et al. 2001). A. terreus infection in harbor porpoises Phocoena phocoena has resulted in severe otitis media (Prahl et al. 2011) and necropurulent pneumonia (Jepson et al. 2000). Aspergillusassociated CNS and lung disease has been linked to CeMV coinfection in striped dolphins (Domingo et al. 1992) and bottlenose dolphins Tursiops truncatus (Cassle et al. 2016). In our Case 1, the lesions observed suggested an aerogenous route of entry and lesion progression from bronchocentric pneumonia to eventual fatal localized angioinvasive aspergillosis. There was no systemic dissemination, and we assume that the severity and extent of pulmonary aspergillosis-associated lesions contributed to death in Case 1. Although quite commonly associated with underlying immunosuppressive conditions (e.g. CeMV), no histomorphological evidence of impaired immunologic response was noted, and PCR analysis for CeMV was negative.

Among the dimorphic systemic fungi, the order Onygenales groups several species known to infect cetaceans, e.g. Blastomyces dermatitides, Coccidioides immitis, Histoplasma capsulatum, Paraccocidioides brasiliensis and Trichophyton sp. (Reidarson et al. 2001, Vilela et al. 2016). Their taxonomy is complex, and the growing number of Onygenales described over the last decades in human and animal species aside from non-biological substrates, e.g. soil, warrants revision (Zhang et al. 2016, Dukik et al. 2017). In Case 2, molecular analysis from the mesenteric lymph node led to identification of a possibly novel Onygenales sequence with greatest nucleotide identity to Nannizziopsiaceae. Although the low identity of the sequence detected prevents drawing any definitive conclusion from a molecular perspective, the morphological features of the fungal elements observed within the necroinflammatory foci in mesenteric lymph node and lung tissue sections were suggestive of Nannizziopsiaceae including ascomatal initials, undulate hyphae, arthroconidia and aleurioconidia (Sigler et al. 2013). By contrast, the fungal morphology in the inflamed testicle tissue slightly differed from the above, including more elongate and flattened hyphae without additional structures. While fungal morphological changes associated with tissue invasion and host inflammatory response could explain this divergence, we cannot entirely rule out the possibility of a fungal coinfection. Fungal culture was not possible in this case. We hypothesize a multifactorial cause of death for this individual, involving chronic systemic fungal infection that could have debilitated and predisposed the animal to blunt trauma of unknown origin.

The ecology and geographical distribution of Onygenales in cetaceans remain poorly understood. Further studies are needed to better delineate the presence and geographic distribution of this order, including the family Nannizziopsiaceae, in marine ecosystems, with special emphasis on transmissibility and pathogenicity in marine mammals.

Stagonosporopsis cucurbitacearum, identified from the lung of case 2, is largely known as a phytopathogenic fungus and has been isolated from healthy human tissues (Park et al. 2012); few reports have linked this species and members of the same genus 
to ocular and lung disease (Ozdemir et al. 2016). Other fungal phytopathogens are well known to cause disease in humans and other animal species, including marine mammals, e.g. Fusarium spp. (Reidarson et al. 2001). In Case 2, morphological identification of hyphae by light microscopy in lung tissue sections was not compatible with this fungus; we surmise that $S$. cucurbitacearum likely represents a contaminant.

In conclusion, these cases widen the repertoire of hyphate fungal etiologies and mycosis-afflicted host records in cetaceans. Herein, we provide the first report of pulmonary aspergillosis by A. fumigatus in an Atlantic spotted dolphin and systemic mycosis by a possibly novel Onygenales in marine mammals. Pathological investigations on stranded cetaceans may benefit from continued monitoring, employing molecular diagnostics and considering fungal culture when possible.

Acknowledgements. We thank the Laboratório de Nectologia/Univille team and Mariana Ebert for their assistance in necropsy procedures, as well as the Projeto Toninhas team, sponsored by Petrobras; and to the Fundo de Apoio à Pesquisa/Univille for supporting cetacean research in the region. The support from the Transpetro team and from the São Francisco do Sul town hall was essential for the whale transport to the university. We very much appreciate the support of FAPESC PAP/UDESC 2015TR286, Coordination for the Improvement of Higher Education Personnel (CAPES), and São Paulo Research Foundation (FAPESP, grants 2014/ 24932-2, 2015/00735-6 and 2017/02223-8). J.D.-D. is the recipient of a post-doctoral fellowship by FAPESP (grant 2017/ 02223-8), and J.L.C.-D. is the recipient of a professorship from the Conselho Nacional de Desenvolvimento Científico e Tecnológico - CNPq (301517/2006-1).

\section{LITERATURE CITED}

Abdo W, Kawachi T, Sakai H, Fukushi H and others (2012) Disseminated mycosis in a killer whale (Orcinus orca). J Vet Diagn Invest 24:211-218

* Barrett T, Visser IKG, Mamaev L, Goatley L, Van Bressem MF, Osterhaus ADME (1993) Dolphin and porpoise morbilliviruses are genetically distinct from phocine distemper virus. Virology 193:1010-1012

Best PB, McCully RM (1979) Zygomycosis (phycomycosis) in a right whale (Eubalaena australis). J Comp Pathol 89: 341-348

Cassle SE, Landrau-Giovannetti N, Farina LL, Leone A and others (2016) Coinfection by Cetacean morbillivirus and Aspergillus fumigatus in a juvenile bottlenose dolphin (Tursiops truncatus) in the Gulf of Mexico. J Vet Diagn Invest 28:729-734

Dagleish MP, Foster G, Howie FE, Reid RJ, Barley J (2008) Fatal mycotic encephalitis caused by Aspergillus fumigatus in a northern bottlenose whale (Hyperoodon ampullatus). Vet Rec 163:602-604
Domingo M, Visa J, Pumarola M, Marco AJ, Ferrer L, Rabanal R, Kennedy S (1992) Pathologic and immunocytochemical studies of morbillivirus infection in striped dolphins (Stenella coeruleoalba). Vet Pathol 29:1-10

* Dukik K, Muñoz JF, Jiang Y, Feng P and others (2017) Novel taxa of thermally dimorphic systemic pathogens in the Ajellomycetaceae (Onygenales). Mycoses 60: 296-309

*Gardes M, Bruns TD (1993) ITS primers with enhanced specificity for basidiomycetes - application to the identification of mycorrhizae and rusts. Mol Ecol 2:113-118

* Guarner J, Brandt ME (2011) Histopathologic diagnosis of fungal infections in the 21st century. Clin Microbiol Rev 24:247-280

Jepson PD, Baker JR, Kuiken T, Simpson VR, Kennedy S, Bennett PM (2000) Pulmonary pathology of harbour porpoises (Phocoena phocoena) stranded in England. Vet Rec 146:721-728

McAloose D, Rago MV, Di Martino M, Chirife A and others (2016) Post-mortem findings in southern right whales Eubalaena australis at Península Valdés, Argentina, 2003-2012. Dis Aquat Org 119:17-36

* Meason-Smith C, Edwards EE, Older CE, Branco M and others (2017) Panfungal polymerase chain reaction for identification of fungal pathogens in formalin-fixed animal tissues. Vet Pathol 54:640-648

Miller WG, Padhye AA, van Bonn W, Jensen E, Brandt ME, Ridgway SH (2002) Cryptococcosis in a bottlenose dolphin (Tursiops truncatus) caused by Cryptococcus neoformans var. gattii. J Clin Microbiol 40:721-724

*Mouton M, Przybylowicz W, Mesjasz-Przybylowicz J, Postma F, Thornton M, Archer E, Botha A (2015) Linking the occurrence of cutaneous opportunistic fungal invaders with elemental concentrations in false killer whale (Pseudorca crassidens) skin. Environ Microbiol Rep 7:728-737

Naota M, Shimada A, Morita T, Kimura K, Ochiai K, Sano A (2009) Granulomatous pericarditis associated with systemic mucormycosis in a finless porpoise (Neophocaena phocaenoides). J Comp Pathol 140:64-66

Ozdemir HG, Kandemir H, Çürük A, Ilkit M, Seyedmousavi S (2016) Infrequent production of xanthomegnin by fungal strains recovered from patients with ocular mycoses. Mycopathologia 181:241-246

* Park HK, Ha MH, Park SG, Kim MN, Kim BJ, Kim W (2012) Characterization of the fungal microbiota (mycobiome) in healthy and dandruff-afflicted human scalps. PLOS ONE 7:e32847

* Prahl S, Jepson PD, Sanchez-Hanke M, Deaville R, Siebert U (2011) Aspergillosis in the middle ear of a harbour porpoise (Phocoena phocoena): a case report. Mycoses 54: e260-e264

Reidarson TH, McBain JF, Dalton LM, Rinaldi MG (2001) Mycotic diseases. In: Dierauf LA, Gulland FMD (eds) CRC handbook of marine mammal medicine. CRC Press, Boca Raton, FL, p 337-355

Robeck TR, Dalton LM (2002) Saksenaea vasiformis and Apophysomyces elegans zygomycotic infections in bottlenose dolphins (Tursiops truncatus), a killer whale (Orcinus orca), and Pacific white-sided dolphins (Lagenorhynchus obliquidens). J Zoo Wildl Med 33:356-366

Sigler L, Hambleton S, Paré JA (2013) Molecular characterization of reptile pathogens currently known as members of the Chrysosporium anamorph of Nannizziopsis vriesii complex and relationship with some human-associated 
isolates. J Clin Microbiol 51:3338-3357

Steininger C, van Lunzen J, Tintelnot K, Sobottka I, Rohde H, Horstkotte MA, Stellbrink HJ (2005) Mycotic brain abscess caused by opportunistic reptile pathogen. Emerg Infect Dis 11:349-350

Vilela R, Bossart GD, St Leger JA, Dalton LM and others (2016) Cutaneous granulomas in dolphins caused by novel uncultivated Paracoccidioides brasiliensis. Emerg Infect Dis 22:2063-2069

Editorial responsibility: Stephen Raverty, Abbotsford, British Columbia, Canada
White TJ, Bruns T, Taylor J (1990) Amplification and direct sequencing of fungal ribosomal RNA genes for phylogenetics. In: Wright DK, Manos MM, Innis MA (eds) PCR protocols: a guide to methods and applications. Academic Press, Orlando, FL, p 315-322

Zhang YW, Chen WH, Zeng GP, Wang YR, Han YF, Qiu SY, Liang ZQ (2016) Two new Chrysosporium (Onygenaceae, Onygenales) from China. Phytotaxa 270: $210-216$

Submitted: September 4, 2017; Accepted: December 27, 2017 Proofs received from author(s): March 10, 2018 